\title{
STAT3, Cten, and lung cancer: Simultaneous excitement and caution
}

\author{
Robert B. Cameron, MD
}

See related article on pages 369-75.

The report in this issue of the Journal of Thoracic and Cardiovascular Surgery by Bennett and colleagues highlights both the promises and the potential pitfalls of genetic data generated from molecular cancer research. The finding that activation of signal transducer and activator of transcription 3 (STAT3) likely contributes to epidermal growth factormediated C-terminal tensinlike protein (Cten) expression and lung cancer invasion and metastasis creates the natural expectation that pharmacologic inhibitors of this pathway will obviously lead to significant improvements in outcomes from lung cancer therapy. Ostensible confirmation of this is provided by Bennett and colleagues through a series of experiments showing STAT3 inhibition with the specific inhibitor S3i-201, which significantly reduced the epidermal growth factor-induced, STAT3-mediated Cten expression in 3 of the 4 human lung cancer cell lines studied.

Although the evidence from this study seems compelling and suitable to motivate the pharmaceutical industry to pursue STAT3 inhibitors, there remain some cautionary points.

From the Division of Thoracic Surgery, Department of Surgery, David Geffen School of Medicine at UCLA, Los Angeles, Calif.

Disclosures: Author has nothing to disclose with regard to commercial support.

Received for publication Sept 16, 2014; accepted for publication Sept 17, 2014; available ahead of print Oct 16, 2014.

Address for reprints: Robert B. Cameron, MD, Division of Thoracic Surgery, Department of Surgery, David Geffen School of Medicine at UCLA, 10780 Santa Monica Blvd, Suite 100, Los Angeles, CA 90025 (E-mail: rcameron@stanfordalumni.org). J Thorac Cardiovasc Surg 2015;149:376-7 0022-5223/\$36.00

Copyright $\subset 2015$ by The American Association for Thoracic Surgery http://dx.doi.org/10.1016/j.jtcvs.2014.09.053
First, Bennett and colleagues' own data are not totally consistent. Admittedly, only 3 of 4 cell lines showed reduction of Cten expression with the use of STAT3 inhibitors. The reason that the A549 cell line did not demonstrate this finding is unclear to the authors and thus the reader. This crucial inconsistency raises the concern that there may be multiple similar pathways that may result in STAT3 activation, thus leading to the possibility that specific inhibitors ultimately will prove ineffective in human clinical trials. Incomplete knowledge of the molecular pathways is a common reason for failure of otherwise apparently successful preclinical compounds. Second, Bennett and colleagues chose a model of in vitro 2-dimensional adherent cultures of defined cell lines. These differ substantially from the reality of the in vivo tumor microenvironment. Numerous reports have documented differential gene expression in 2-dimensional versus 3-dimensional and multicellular tissue environments (Figure 1), raising the specter that completely different data could be generated with other potential preclinical cancer models. ${ }^{1-3}$ Finally, the heterogeneity of the tumor microenvironment suggests that tumor cells are not identical to defined cell lines. Varying populations of cancer cells, such as cancer stem cells, may have variable molecular pathways and without a better understanding of the entire cancer cell population may lead to rapid failure of experimental agents in early phase II clinical trials.

Despite these cautionary notes regarding this promising study, the finding that activation of STAT3 likely contributes to epidermal growth factor-mediated Cten expression and lung cancer invasion and metastasis is a crucial piece of information in fight against lung cancer. Although genetic mechanisms of cancer may not be the entire answer for cancer therapy, the information from studies like these

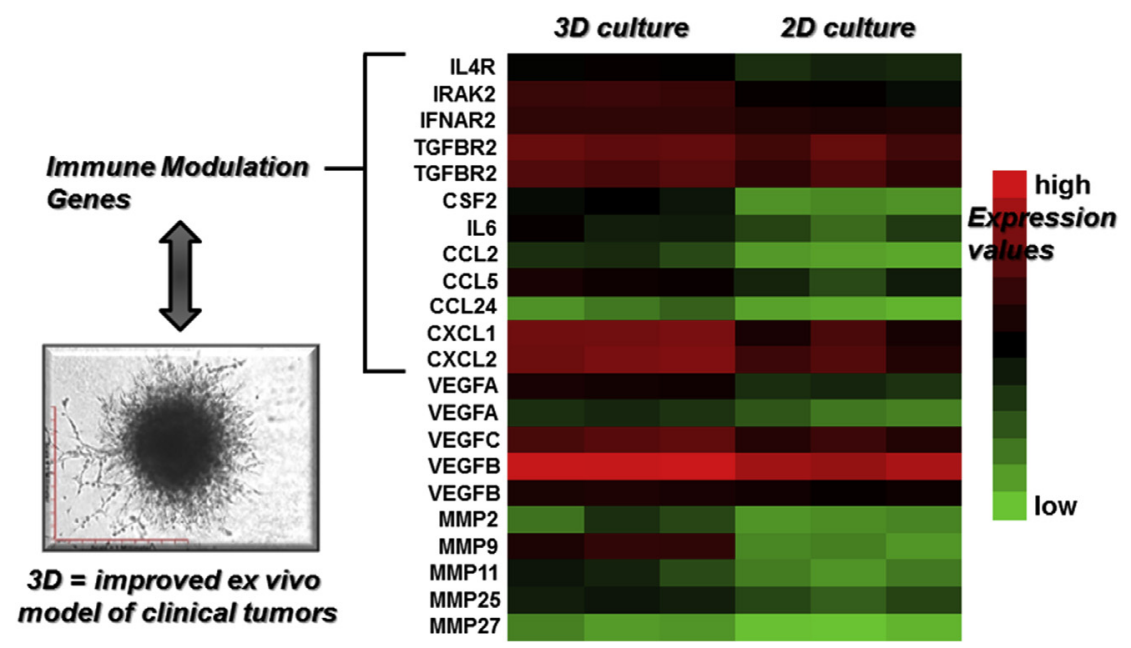

FIGURE 1. Demonstration of differential gene expressions in simultaneous 2-dimensional (2D) adherent and 3-dimensional $(3 D)$ spheroid tumor cultures. 
provide knowledge that one day may provide better individualized therapy and incremental improvements in lung cancer survival.

\section{References}

1. Creighton C, Kuick R, Misek DE, Rickman DS, Brichory FM, Rouillard JM, et al. Profiling of pathway-specific changes in gene expression following growth of human cancer cell lines transplanted into mice. Genome Biol. 2003;4:R46.

2. Godugu C, Patel AR, Desai U, Andey T, Sams A, Singh M. AlgiMatrix ${ }^{\mathrm{TM}}$ based 3D cell culture system as an in-vitro tumor model for anticancer studies. PLoS One. 2013;8:e53708

3. Mancini R, Giarnieri E, De Vitis C, Malanga D, Roscilli G, Noto A, et al. Spheres derived from lung adenocarcinoma pleural effusions: molecular characterization and tumor engraftment. PLoS One. 2011;6:e21320. 